\title{
Pengaruh Faktor-Faktor Atraksi Amenitas Dan Aksesbilitas Terhadap Strategi Pengembangan Wisata Halal Bromo
}

\author{
Dian Cahyo Prabowo, Ernani Hadiyati, Sugeng Mulyono, Ahmad \\ Program Pasca Sarjana Magister Manajemen Universitas Gajayana Malang \\ Email: diancahyoprabowo@gmail.com
}

\begin{abstract}
Nowadays, the concept of Islamic economics is an important part of global economic life. In the concept of Islamic economics, there is a concept of halal. The concept of halal in Islamic economics has been developed into various products including banking, hotels/lodging, insurance and tourism in term of syariah. Halal tourism is one of the new phenomena in the tourism sector. One of the tourist areas that developed this halal concept is Mount Bromo tourism. The development of the concept of halal tourism on Mount Bromo is very interesting to study in relation to the different characteristics between the majority of the population around Mount Bromo who are Hindus and the target tourists who are Moslem. This study aims to examine and analyze the influence of attractions, amenities, and accessibility on the development strategy of Mount Bromo halal tourism. Attraction means anything that has uniqueness, beauty, and value in the form of a diversity of natural, cultural, and man-made wealth that is the target or purpose of a tourist visit. Amenities are various facilities that must be provided by a tourist destination. Accessibility is the ability to reach a certain tourist destination. This explanatory research was conducted in the tourist area of Mount Bromo in 2019. The type of data in this study is qualitative which were processed into quantitative data. Data were collected through a questionnaire distribution method. The variables in this study were measured using a Likert scale. Furthermore, the data were analyzed by using the SPSS 18 program (Statistical Product and Service Solution). The results of this study are: 1) Attraction variables have a positive and significant effect on the Development Strategy for halal tourism in Mount Bromo; 2) The amenities variable directly has a positive and significant effect on the Development Strategy for halal tourism in Mount Bromo; 3) The accessibility variable has a negative and insignificant effect directly on the Development Strategy for halal tourism in Mount Bromo; 4) The variables of attractions, amenities and accessibility together have a positive and significant effect on the development strategy of halal tourism in Mount Bromo.
\end{abstract}

Keywords: Attractions-Amenities-Accessibility, Halal Tourism Development Strategy, Mount Bromo

\section{PENDAHULUAN}

Pada masa sekarang ini, konsep ekonomi islam menjadi bagian yang penting dalam kehidupan ekonomi global. Dalam konsep ekonomi islam dikenal adanya konsep halal. Dalam bahasa Arab, halal mengandung arti diperbolehkan sesuai dengan syariah islam. Konsep halal dalam ekonomi islam ini telah dikembangkan ke berbagai produk diantaranya transaksi perbankan, perhotelan/penginapan, asuransi dan pariwisata dengan istilah syariah. Oleh karena itu, bermunculan istilah Bank Syariah, Hotel Syariah, Asuransi Syariah, begitu pula dengan Pariwisata Syariah atau Pariwisata Halal. 
Pariwisata Halal menjadi salah satu fenomena baru dalam bidang pariwisata Konsep pariwisata ini bersifat melengkapi konsep pariwisata sebelumnya serta diharapkan dapat memperluas pangsa pasar destinasi wisata yang ada. Dengan kata lain, pariwisata halal bukan merupakan produk wisata ekslusif yang akan mengancam keberlangsungan industri pariwisata pada umumnya. Bahkan, konsep pariwisata halal bermaksud menghargai dan menjunjung tinggi prinsip-prinsip, budaya, serta nilai-nilai islam yang dalam hal ini diterapkan pada dunia pariwisata.

Salah satu daerah wisata yang mengembangkan konsep halal ini adalah pariwisata di Gunung Bromo. Sementara, pengembangan konsep pariwisata halal di Gunung Bromo menjadi sangat menarik untuk dikaji terkait dengan karakteristik yang berbeda antara mayoritas penduduk di sekitar Gunung Bromo yang beragama Hindu dengan target wisatawan yang beragama Islam. Destinasi wisata Gunung Bromo memiliki target meningkatkan jumlah kunjungan wisatawan baik nusantara maupun mancanegara. Dari mancanegara, terdapat Malaysia, Singapura, Tiongkok, Jepang, negara-negara Eropa, serta Timur Tengah. Sedangkan, dari dalam negeri, diharapkan terjadi peningkatan kunjungan wisata dari kota-kota di Pulau Jawa dan Bali (Ratman, 2016). Dalam hal ini, ada dua target negara asal wisatawan yang mayoritas penduduknya muslim, yaitu Malaysia dan Timur Tengah. Oleh karena itu, dalam pengembangan destinasi wisata Gunung Bromo menjadi suatu keniscayaan yang tidak bisa diabaikan dengan menawarkan produk pariwisata halal.

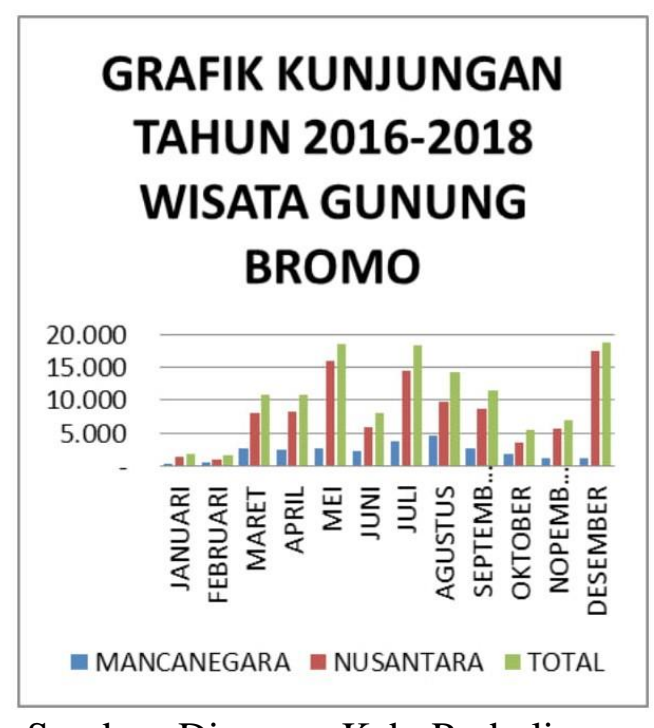

Sumber: Dispopar Kab. Probolinggo

Gambar 1. Grafik Kunjungan Wisata Gunung Bromo Tahun 2016-2018

Dengan perbedaan karakteristik tersebut timbul permasalahan antara lain apakah atraksi wisata Gunung Bromo berpengaruh terhadap strategi pengembangan wisata halal? Apakah amenitas wisata Gunung Bromo berpengaruh terhadap strategi pengembangan wisata halal? Apakah aksesbilitas wisata Gunung Bromo berpengaruh terhadap strategi pengembangan wisata halal? serta apakah atraksi, amenitas dan aksesbititas wisata Gunung Bromo secara simultan berpengaruh terhadap strategi pengembangan wisata halal?

Penelitian ini bertujuan untuk menguji dan menganalisis berbagai permasalahan tersebut. Penelitian ini dilakukan dengan cara menganalisis persepsi masyarakat setempat terhadap wisata halal serta membandingkannya dengan persepsi wisatawan sehingga penelitian ini diharapkan akan menghasilkan suatu strategi pemasaran yang tepat untuk meningkatkan daya saing wisata Gunung Bromo di masa mendatang. 


\section{KAJIAN PUSTAKA}

Pemasaran merupakan sebuah aktivitas yang memiliki tujuan untuk mencapai sasaran perusahaan, yang dilakukan dengan cara mengantisipasi kebutuhan pelanggan atau klien serta mengarahkan banyak aliran barang dan jasa untuk memenuhi kebutuhan pelanggan atau klien dari produsen (Cannon et al, 2008:8). Pemasaran berorientasi pada pelanggan sebagai lingkungan eksternal (Tjiptono, 2007:3). Hal ini berkaitan dengan anggapan bahwa pelanggan adalah konsumen yang bersedia membeli produk untuk memenuhi kebutuhan dan keinginannya serta memberikan kepuasan terhadapnya. Jadi, tujuan perusahaan adalah memuaskan pelanggan melalui pemahaman perilaku konsumen secara menyeluruh dalam aktivitas pemasaran. Sedangkan, bauran pemasaran adalah seperangkat elemen yang dapat digunakan oleh pemasar untuk membentuk karakteristik jasa yang ditawarkan kepada pelanggan. Elemen strategi bauran pemasaran meliputi products, pricing, promotion, place, people, physical Evidence, process, customer Service (7P+1C) (Tjiptono, 2004:30).

Sementara, dalam bidang pariwisata, dikenal istilah atraksi atau daya tarik wisata. Atraksi memiliki arti segala sesuatu yang mempunyai keunikan, keindahan, serta nilai berupa keanekaragaman kekayaan alam, budaya, dan hasil buatan manusia yang menjadi sasaran atau tujuan kunjungan wisata (UU No.10 Tahun 2009). Jadi atraksi menjadi hal utama yang bersifat menarik dari suatu destinasi wisata. Atraksi merupakan motivator kunci untuk mengunjungi sebuah destinasi (Crouch \& Ritchie dalam Abdulhaji \& Yusuf, 2016), serta menjadi alasan pokok bagi pengunjung dalam memilih sebuah destinasi dibanding lainnya (Goeldner et al dalam Abdulhaji, 2016), sehingga menjadi daya tarik wisatawan untuk mengunjungi daerah wisata tersebut (Roger \& Slinn dalam Abdulhaji \& Yusuf, 2016).

Terdapat lima kelompok atraksi yaitu kebudayaan, alam, acara, rekreasi, dan hiburan. Sedangkan, atraksi wisata yang baik semestinya dapat mendatangkan wisatawan sebanyakbanyaknya, membuat mereka bertahan di tempat wisata tersebut dalam waktu yang cukup lama, serta memberikan nilai kepuasan kepada wisatawan yang berkunjung (Soekadijo dalam Abdulhaji \& Yusuf, 2016). Selain itu, terdapat amenitas atau berbagai fasilitas yang harus disediakan oleh suatu destinasi wisata. Fasilitas ini meliputi sarana akomodasi, restoran, toilet umum, rest area, souvenir shop, tempat parkir, tempat ibadah dan lain-lain yang sebaiknya harus tersedia di sebuah destinasi wisata.

Kedua hal tersebut diperkuat dengan adanya aksesbilitas yang baik pula, yaitu kemampuan untuk mencapai suatu destinasi wisata tertentu (Spillane, 1997:37). Aksesbilitas dapat diukur dengan parameter seperti kemiringan jalan dan lokasi objek wisata, selain akses mudah, kualitas jalan, fasilitas parkir, dan waktu mengemudi (Çakici et al, 2007:139). Selain hal-hal tersebut, dalam pengembangan pariwisata diperlukan strategi atau perencanaan pengembangan. Tahapan pelaksanaan dalam perencanaan pengembangan pariwisata meliputi Marketing Research, Situational Analysis, Marketing Target, Tourism Promotion, dan Pemberdayaan masyarakat dan swasta dalam promosi dan Marketing.

Berdasarkan landasan teori, penelitian ini memiliki kerangka konseptual yang menggambarkan hubungan independent variable terhadap dependent variable yang ditunjukkan pada Gambar 2. Hipotesis pada penelitian ini adalah sebagai berikut.

H1: Atraksi wisata Gunung Bromo berpengaruh secara parsial terhadap strategi pengembangan wisata halal;

H2: Amenitas wisata Gunung Bromo berpengaruh secara parsial terhadap strategi pengembangan wisata halal;

H3: Aksebilitas wisata Gunung Bromo berpengaruh secara parsial terhadap strategi pengembangan wisata halal; 
H4: Aktraksi, Amenitas dan Aksesbilitas wisata Gunung Bromo berpengaruh secara simultan terhadap stategi pengembangan wisata halal.

Sementara, kebaruan pada penelitian ini dibandingkan dengan penelitian-penelitian sebelumnya adalah bahwa penelitian ini menganalisis tentang pengaruh faktor-faktor atraksi, amenitas dan aksesbilitas terhadap strategi pengembangan wisata halal Gunung Bromo, yang belum pernah dilakukan sebelumnya.

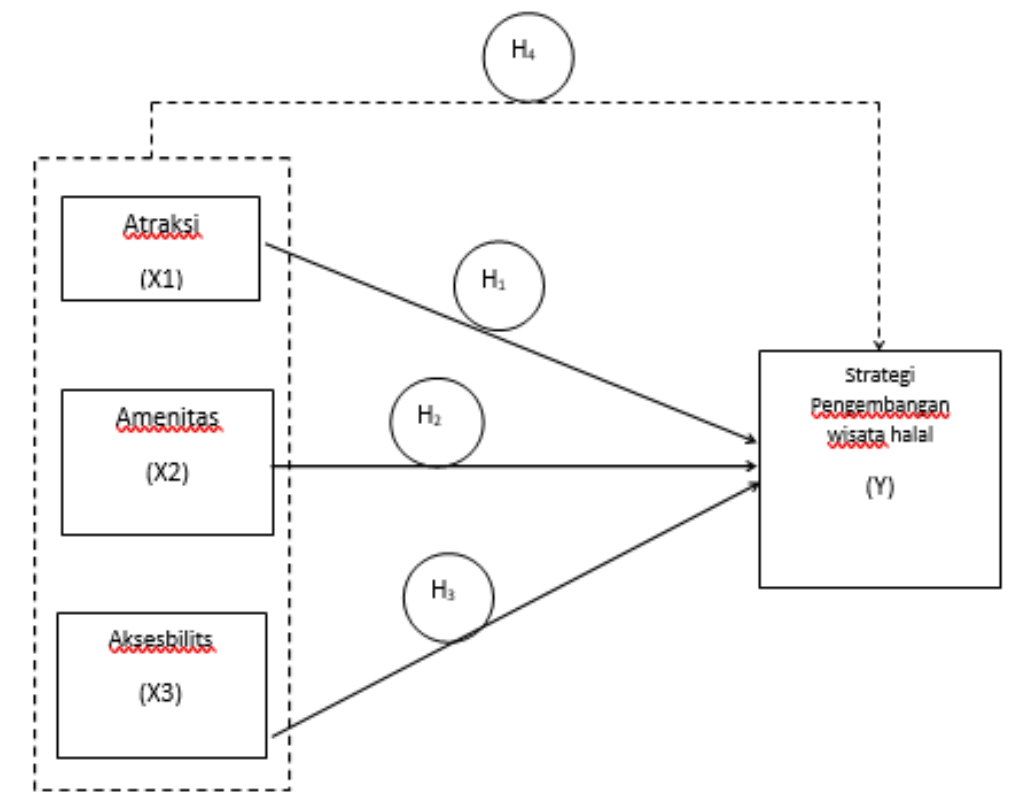

Sumber: Diolah Oleh Peneliti (2019).

Keterangan:

Berpengaruh secara parsial

Berpengaruh secara simultan

Gambar 2. Kerangka Konseptual

\section{METODE PENELITIAN}

Penelitian ini merupakan penelitian eksplanatori yang mengambil lokasi penelitian di daerah wisata Gunung Bromo. Sedangkan, penelitian ini dilakukan pada tahun 2019. Jenis data pada penelitian ini bersifat kualitatif yang diolah menjadi data kuntitatif. Data kuantitatif adalah pilihan jawaban responden melalui kuesioner. Data kuantitatifnya berupa nilai yang diberikan pada hasil kuesioner. Jadi metode pengumpulan data pada penelitian ini adalah dengan penyebaran kuesioner kepada responden yaitu pengguna jasa wisata Gunung Bromo. Jumlah responden pada penelitian ini adalah 140 responden dengan pertimbangan bahwa terdapat 14 item pertanyaan pada kuesioner, sedangkan ukuran responden yang ideal dan representatif adalah jumlah indikator pada variabel dikalikan 5 pada batas minimal atau 10 pada batas maksimal (Hair et al, 2010). Jadi sejumlah 140 responden didapatkan dari jumlah indikator variabel yaitu 14 x $10=140$.

Teknik sampling menggunakan non probability sampling (Sugiyono, 2012:122) dan accidental sampling (Riduwan, 2012:63) dengan kriteria penggunan jasa wisata Gunung Bromo Nusantara. Sedangkan operasional variabel yang dijadikan acuan dalam penyusunan kuesioner sebagai alat ukur penelitian ini ditunjukkan pada tabel 1. 
Tabel 1. Definisi Operasional Variabel

\begin{tabular}{|c|c|c|c|}
\hline No & Variabel & Sub variabel & Indikator \\
\hline 1 & Atraksi & $\begin{array}{l}\text { 1. Alam } \\
\text { 2. Budaya } \\
\text { 3. Buatan }\end{array}$ & $\begin{array}{l}\text { 1. Pertunjukan Seni dan Budaya serta } \\
\text { atraksi yang tidak bertentangan } \\
\text { dengan syariat Islam } \\
\text { 2. Terjaga kebersihan sanitasi dan } \\
\text { lingkungan } \\
\text { 3. Terdapat Masjid dengan adanya } \\
\text { petunjuk Qiblat/tempat ibadah yang } \\
\text { layak dan bersih di obyek wisata } \\
\text { 4. Tersedia tempat wudhu/sarana bersuci } \\
\text { yang layak dengan air yang cukup di } \\
\text { obyek wisata } \\
\text { 5. Tersedia makanan dan minuman halal }\end{array}$ \\
\hline 2 & Amenitas & $\begin{array}{l}\text { 1. Perhotelan } \\
\text { 2. Restaurant/Penyedia } \\
\text { makanan dan } \\
\text { minuman } \\
\text { 3. Biro Perjalanan } \\
\text { Wisata } \\
\text { 4. Spa } \\
\text { 5. Pramuwisata }\end{array}$ & $\begin{array}{l}\text { 1. Tersedia fasilitas yang layak untuk } \\
\text { bersuci } \\
\text { 2. Terjamin kehalalan makanan dan } \\
\text { minuman dengan sertifikasi halal MUI } \\
\text { 3. Menyediakan paket perjalanan/wisata } \\
\text { yang sesuai dengan kriteria pariwisata } \\
\text { halal } \\
\text { 4. Tersedianya terapis yang khusus pria } \\
\text { atau khusus wanita } \\
\text { 5. Mampu melaksanakan nilai-nilai } \\
\text { Islami dalam menjalankan tugas }\end{array}$ \\
\hline 3 & A & $\begin{array}{l}\text { 1. Akses mudah } \\
\text { 2. Kualitas Jalan } \\
\text { 3. Fasilitas Parkir } \\
\text { 4. Waktu Mengemudi. }\end{array}$ & $\begin{array}{l}\text { 1. Adanya ketersediaan transportasi yang } \\
\text { memadahi } \\
\text { 2. Keadaan jalan yang nyaman dan tidak } \\
\text { berlubang } \\
\text { 3. Ketersediaan area parkir yang luas } \\
\text { 4. Adanya keamaan di sekitar kawasan } \\
\text { wisata bagi pengemudi }\end{array}$ \\
\hline 4 & $\begin{array}{l}\text { Strategi } \\
\text { Pengemban } \\
\text { gan } \\
(\mathrm{Y})\end{array}$ & $\begin{array}{l}\text { 1. Faktor kealamiahan } \\
\text { (Naturalism) } \\
\text { 2. Faktor keunikan } \\
\text { (Uniqueness), } \\
\text { 3. Faktor optimalisasi } \\
\text { lahan } \\
\text { (Areaoptimalsation) } \\
\text { 4. Faktor pemerataan }\end{array}$ & $\begin{array}{l}\text { 1. Kawasan Gunung Bromo masih asri } \\
\text { tanpa polusi } \\
\text { 2. Kawasan Gunung Bromo memiliki } \\
\text { keunikan yang tidak ada di wilayah } \\
\text { wisata lain } \\
\text { 3. Lahan di sekitar wilayah wisata dapat } \\
\text { dioptimalkan dengan baik } \\
\text { 4. Banyaknya matapencaharian yang } \\
\text { beragam }\end{array}$ \\
\hline
\end{tabular}

Sumber: Data diolah peneliti (2019)

Variabel pada penelitian ini diukur dengan menggunakan skala likert (Sugiyono, 2011:136-137). Skala likert berbentuk pertanyaan dalam bentuk ranking yang ditunjukkan pada tabel 2. 
Tabel 2. Instrumen Skala Likert

\begin{tabular}{|c|c|c|}
\hline No. & Pertanyaan & Skor \\
\hline 1. & Sangat Setuju & 5 \\
\hline 2. & Setuju & 4 \\
\hline 3. & Kurang Setuju & 3 \\
\hline 4. & Tidak Setuju & 2 \\
\hline 5. & Sangat Tidak Setuju & 1 \\
\hline
\end{tabular}

Sumber: (Sugiyono, 2011:137)

Selanjutnya data dari hasil kusioner ditabulasikan dan dihitung dengan menggunakan program SPSS 18 (Statistical Product and Service Solution) sebagai metode analisis data penelitian ini. Uji validitas data menggunakan ketentuan jika nilai signifikan correlation < 0,05 maka item variabel disimpulkan valid. Uji reliabilitas diukur dengan melihat cronbach alpha. Variabel dinyatakan reliabel jika memberikan nilai cronbach alpha > 0,60 (Ghozali, 2005:87). Teknik analisis data distribusi frekuensi digunakan untuk menyusun data berdasarkan kelas-kelas tertentu (Hasan, 2005:41). Distribusi frekuensi data penelitian ini dikelompokkan menjadi beberapa kategori yang menunjukkan banyaknya data pada setiap kategori. Setiap data tidak dapat dimasukkan ke dalam dua atau lebih kategori (Suharyadi dan Purwanto, 2003: 25). Sedangkan, teknik analisis regresi linier berganda digunakan untuk menguji besarnya sumbangan (kontribusi) yang ditunjukkan oleh koefisien jalur pada setiap diagram jalaur dari hubungan antar variabel, dengan struktur model:

$$
\mathrm{Y}=\alpha+\mathrm{b} 1 . \mathrm{X} 1+\mathrm{b} 2 . \mathrm{X} 2+\mathrm{b} 3 . \mathrm{X} 3+\mathrm{e},
$$

dengan keterangan sebagai berikut:

$\alpha \quad=$ Konstanta

b1, b2, b3, = Nilai koefisien masing-masing variabel bebas

$\mathrm{Y} \quad=$ Strategi Pengembangan wisata halal

$\mathrm{X} 1=$ Atraksi

$\mathrm{X} 2=$ Amenitas

X3 = Aksesbilitas

$\mathrm{e} \quad=$ Error atau Nilai Sisa

\section{HASIL DAN PEMBAHASAN}

Taman Nasional Gunung Bromo Tengger Semeru merupakan salah satu destinasi wisata internaional yang berada pada empat wilayah administratif, yaitu Kabupaten Pasuruan, Malang, Lumajang, dan Probolinggo. Taman nasional ini ditetapkan memiliki luas 50.276.3 ha dengan bentangan sekitar 20-30 km dari barat ke timur, dan sekitar $40 \mathrm{~km}$ dari utara ke selatan. Kawasan ini memiliki kaldera lautan pasir seluas sekitar 6290 ha. Batas kaldera tersebut berupa dinding terjal setinggi sekitar 200-700 m. Kawasan Tengger Semeru ditetapkan menjadi taman nasional pada tanggal 14 Oktober 1982 di Bali pada Kongres Taman Nasional Sedunia. Sebelumnya, daerah ini adalah kawasan hutan yang memiliki fungsi sebagai cagar alam dan hutan wisata, baik sebagai hutan lindung maupun hutan 
produksi. Ditindaklanjuti oleh Pemerintah Indonesia, pada tanggal 12 November 1992, kawasan ini diresmikan menjadi taman nasional.

Pada penelitian yang bertujuan untuk mengembangkan pariwisata halal di kawasan Bromo Tengger Semeru ini, karakteristik responden ditetapkan berdasarkan jenis kelamin, umur, pendidikan terakhir, dan profesi. Deskripsi tentang karakteristik responden tersebut dijabarkan pada tabel 3, 4, 5, dan 6 .

Tabel 3. Karakteristik Jenis Kelamin Responden

\begin{tabular}{|c|c|c|c|}
\hline No & Jenis Kelamin & Frekuensi ( orang ) & Prosentase \\
\hline 1 & Laki-Laki & 83 & $59 \%$ \\
\hline 2 & Perempuan & 57 & $41 \%$ \\
\hline \multicolumn{2}{|c|}{ Jumlah } & $\mathbf{1 4 0}$ & $\mathbf{1 0 0 \%}$ \\
\hline
\end{tabular}

Sumber: Data diolah peneliti (2019)

Dari sejumlah 140 responden yang diteliti, berdasarkan jenis kelamin terdapat 83 responden laki-laki (59\%) dan 57 responden perempuan (41\%).

Tabel 4. Karakteristik Usia Responden

\begin{tabular}{|c|c|c|c|}
\hline No & Usia & Frekuensi (orang) & Prosentase \\
\hline 1 & 17 atau lebih muda & 5 & $3,6 \%$ \\
\hline 2 & $18-24$ tahun & 77 & $55 \%$ \\
\hline 3 & $25-34$ tahun & 46 & $32,9 \%$ \\
\hline 4 & $35-44$ tahun & 10 & $7,1 \%$ \\
\hline 5 & 45 atau lebih tua & 2 & $1,4 \%$ \\
\hline \multicolumn{2}{|r|}{ Jumlah } & $\mathbf{1 4 0}$ & $\mathbf{1 0 0} \%$ \\
\hline
\end{tabular}

Sumber: data primer, diolah (2019).

Berdasarkan usia, terdapat 5 responden $(3,6 \%)$ berusia 17 tahun atau lebih muda, 77 responden $(55 \%)$ berusia 18-24 tahun, 46 responden $(32,9 \%)$ berusia $25-34$ tahun, 10 responden $(7,1 \%)$ berusia $35-44$ tahun, dan 2 responden $(1,4 \%)$ berusia 45 atau lebih tua.

Tabel 5. Karakteristik Pendidikan Terakhir Responden

\begin{tabular}{|c|c|c|c|}
\hline No & Pendidikan terakhir & Frekuensi (orang) & Prosentase \\
\hline 1 & SMP & 9 & $6,4 \%$ \\
\hline 2 & SMA & 69 & $49,3 \%$ \\
\hline 3 & D3 & 42 & $30 \%$ \\
\hline 4 & S1 & 20 & $14,3 \%$ \\
\hline 5 & S2 & 0 & $0 \%$ \\
\hline \multicolumn{2}{r|}{ Jumlah } & $\mathbf{1 4 0}$ & $\mathbf{1 0 0} \%$ \\
\hline
\end{tabular}

Sumber: data primer, diolah (2019).

Sedangkan, berdasarkan pendidikan terakhirnya, terdapat 9 responden $(6,4 \%)$ berpendidikan SMP, 69 responden (49,3\%) berpendidikan SMA, 42 responden (30\%) berpendidikan D3, 20 responden $(14,3 \%)$ berpendidikan $\mathrm{S} 1$, dan tidak ada responden yang berpendidikan $\mathrm{S} 2$. 
Tabel 6. Karakteristik Profesi Responden

\begin{tabular}{|c|c|c|c|}
\hline No & profesi & frekuensi (orang) & Prosentase \\
\hline 1 & Pelajar/Mahasiswa & 78 & $55,8 \%$ \\
\hline 2 & Pegawai Negeri & 21 & $15 \%$ \\
\hline 3 & Pegawai Swasta & 15 & $10,7 \%$ \\
\hline 4 & Wiraswasta & 26 & $18,5 \%$ \\
\hline 5 & Lain-lain & 0 & $0 \%$ \\
\hline \multicolumn{2}{r|}{ Jumlah } & $\mathbf{1 4 0}$ & $\mathbf{1 0 0 \%}$ \\
\hline
\end{tabular}

Sumber: data primer, diolah (2019)

Selanjutnya, berdasarkan profesinya, terdapat 78 pelajar/mahasiswa $(55,8 \%), 21$ pegawai negeri (15\%), 15 pegawai swasta $(10,7 \%)$, serta 26 wiraswasta $(18,5 \%)$.

Dari hasil penghitungan skor kuesioner, uji instrumen dilakukan berdasarkan uji validitas dan uji reliabilitas. Berdasarkan uji validitas, standar valid dengan harga korelasi pearson (r) lebih besar dari 0,30 atau memiliki nilai probabilitas korelasi dibawah 0,05 didapatkan hasil seperti ditunjukkan pada tabel 7.

Tabel 7. Hasil Uji Validitas

\begin{tabular}{|c|c|c|c|c|}
\hline Variabel & Indikator & Correlation & p-value & Hasil Uji \\
\hline \multirow{4}{*}{$\begin{array}{c}\text { Atraksi } \\
\text { (X1) }\end{array}$} & $\mathrm{X} 1.1$ & 0,858 & 0,000 & valid \\
\cline { 2 - 5 } & $\mathrm{X} 1.2$ & 0,693 & 0,000 & valid \\
\cline { 2 - 5 } & $\mathrm{X} 1.3$ & 0,746 & 0,000 & valid \\
\cline { 2 - 5 } & $\mathrm{X} 1.4$ & 0,850 & 0,000 & valid \\
\cline { 2 - 5 } & $\mathrm{X} 1.5$ & 0,934 & 0,000 & valid \\
\cline { 2 - 5 } & $\mathrm{X} 2.1$ & 0,796 & 0,000 & valid \\
\cline { 2 - 5 } & $\mathrm{X} 2.2$ & 0,796 & 0,000 & valid \\
\cline { 2 - 5 } Amenitas (X2) & $\mathrm{X} 2.3$ & 0,824 & 0,000 & valid \\
\cline { 2 - 5 } & $\mathrm{X} 2.4$ & 0.785 & 0,000 & valid \\
\hline \multirow{4}{*}{ Aksesbilitas (X3) } & $\mathrm{X} 3.5$ & 0,918 & 0,000 & valid \\
\cline { 2 - 5 } & $\mathrm{X} 3.2$ & 0,728 & 0,000 & valid \\
\cline { 2 - 5 } & $\mathrm{X} 3.3$ & 0,696 & 0,000 & valid \\
\cline { 2 - 5 } & $\mathrm{X} 3.4$ & 0,840 & 0,000 & valid \\
\cline { 2 - 5 } & $\mathrm{Y} 1$ & 0,811 & 0,000 & valid \\
\cline { 2 - 5 } & $\mathrm{Y} 2$ & 0,827 & 0,000 & valid \\
\cline { 2 - 5 } & $\mathrm{Y} 3$ & 0,772 & 0,000 & valid \\
\cline { 2 - 5 } Strategi & $\mathrm{Y} 4$ & 0,761 & 0,000 & valid \\
\hline
\end{tabular}

Sumber: data primer, diolah (2019)

Pada tabel 7 ditunjukkan hasil uji validitas masing-masing variabel. Hasilnya adalah bahwa variabel Atraksi (X1) berjumlah 5 item, variabel Amenitas (X2) berjumlah 5 item, variabel Aksesbilitas (X3) berjumlah 4 item, variabel Strategi Pengembangan (Y) berjumlah 4 item, serta semua item dari masing-masing variabel dinyatakan valid karena memiliki koefisien korelasi pearson $(r)>0,30$ dan memliki probabilitas $(p$-value) $<0,05$. Hasil uji validitas ini 
menunjukkan bahwa seluruh item pertanyaan dalam kuesioner penelitian dapat digunakan dalam analisis selanjutnya.

Sedangkan uji reliabilitas dengan standar reliabel nilai cronbach alpha $>0,60$ ditunjukkan pada tabel 8 .

Tabel 8. Hasil Uji Reliabilitas

\begin{tabular}{|c|c|c|c|}
\hline No & Variabel & Cronbach Alpha & Hasil \\
\hline 1 & Atraksi (X1) & 0,857 & Reliabel \\
\hline 2 & Amenitas (X2) & 0,878 & Reliabel \\
\hline 3 & Aksesbilitas (X3) & 0,772 & Reliabel \\
\hline 4 & Strategi Pengembangan (Y) & 0,723 & Reliabel \\
\hline
\end{tabular}

Sumber: data primer, diolah (2019)

Berdasarkan uji reliabilitas yang ditunjukkan pada tabel 8, didapatkan hasil perhitungan yang menunjukan seluruh variabel yang terdiri dari Atraksi (X1) memiliki hasil nilai Cronbach Alpha 0,857. Variabel Amenitas (X2) memiliki hasil nilai Cronbach Alpha 0,878 Variabel Aksesbilitas (X3) memiliki hasil nilai Cronbach Alpha 0,772. Sedangkan, variabel Strategi Pengembangan (Y) memiliki hasil nilai Cronbach Alpha 0,723. Hal ini berarti bahwa seluruh variabel dari penelitian tersebut memiliki Cronbach Alpha > 0,60 dengan demikian seluruh variabel yang ada dapat dinyatakan reliabel dan dapat dilanjutkan guna analisis penelitian selanjutnya.

Selanjutnya, hasil pengolahan data kuesioner dari 140 responden tentang Atraksi dijelaskan melalui deskripsi jawaban dari 5 pertanyaan. Hasil pengolahan perhitungannya dapat dilihat pada tabel 9. 
Tabel 9. Hasil Diskripsi Jawaban Responden Tentang Atraksi (X1)

\begin{tabular}{|c|c|c|c|c|c|c|c|c|c|c|c|}
\hline \multirow[t]{2}{*}{ Indikator } & \multicolumn{2}{|c|}{ SS } & \multicolumn{2}{|c|}{$\mathbf{S}$} & \multicolumn{2}{|c|}{ CS } & \multicolumn{2}{|c|}{ TS } & \multicolumn{2}{|c|}{ STS } & \multirow{2}{*}{$\begin{array}{c}\text { Rata - } \\
\text { rata }\end{array}$} \\
\hline & $\mathbf{F}$ & $\%$ & $\mathbf{F}$ & $\%$ & $\mathbf{F}$ & $\%$ & $F$ & $\%$ & $\mathbf{F}$ & $\%$ & \\
\hline $\begin{array}{l}\text { Pertunjukan Seni } \\
\text { dan Budaya serta } \\
\text { atraksi yang tidak } \\
\text { bertentangan } \\
\text { dengan syariat } \\
\text { Islam }\end{array}$ & 0 & 0,0 & 0 & 0,0 & 31 & 22,1 & 84 & 60,0 & 25 & 17,9 & 3,96 \\
\hline $\begin{array}{l}\text { Terjaga kebersihan } \\
\text { sanitasi dan } \\
\text { lingkungan }\end{array}$ & 0 & 0,0 & 0 & 0,0 & 5 & 3,6 & 113 & 80,7 & 22 & 15,7 & 4,12 \\
\hline $\begin{array}{l}\text { Terdapat Masjid } \\
\text { dengan adanya } \\
\text { petunjuk } \\
\text { Qiblat/tempat } \\
\text { ibadah yang layak } \\
\text { dan bersih di obyek } \\
\text { wisata }\end{array}$ & 0 & 0,0 & 0 & 0,0 & 1 & 7,0 & 110 & 78,6 & 29 & 20,7 & 4,20 \\
\hline $\begin{array}{l}\text { Tersedia tempat } \\
\text { wudhu/sarana } \\
\text { bersuci yang layak } \\
\text { dengan air yang } \\
\text { cukup di obyek } \\
\text { wisata }\end{array}$ & 0 & 0,0 & 0 & 0,0 & 24 & 17,1 & 101 & 72,1 & 15 & 10,7 & 3,94 \\
\hline $\begin{array}{l}\text { Tersedia makanan } \\
\text { dan minuman halal }\end{array}$ & 0 & 0,0 & 0 & 0,0 & 20 & 14,3 & 98 & 70,0 & 22 & 15,7 & 4,01 \\
\hline & & & & and & Tea & & & & & & 4,04 \\
\hline
\end{tabular}

Sumber: data primer, diolah (2019)

Berdasarkan tabel 9 dinyatakan bahwa hasil analisis berdasarkan variabel Atraksi dari jawaban responden yang memiliki nilai rata-rata skor tertinggi terdapat pada indikator pertanyaan ketiga, yaitu Terdapat Masjid dengan adanya petunjuk Qiblat/tempat ibadah yang layak dan bersih di obyek wisata. Nilai rata-rata skornya adalah 4,20\%. Sedangkan, nilai rata-rata skor terendah terdapat pada indikator pertanyaan keempat, yaitu Tersedia tempat wudhu/sarana bersuci yang layak dengan air yang cukup di obyek wisata, sebesar 3,94\%. Nilai tersebut membuktikan bahwa responden menyetujui bahwa Masjid yang memiliki petunjuk Qiblat/tempat ibadah yang layak dan bersih menjadi pilihan tertinggi untuk memperkuat stategi pengembangan di destinasi wisata Gunung Bromo.

Berikutnya, hasil pengolahan data tentang Amenitas (X2), hasilnya dideskripsikan pada tabel 10 berikut. 
Tabel 10. Hasil Deskripsi Jawaban Responden tentang Amenitas (X2)

\begin{tabular}{|c|c|c|c|c|c|c|c|c|c|c|c|}
\hline \multirow[t]{2}{*}{ Indikator } & \multicolumn{2}{|c|}{ SS } & \multicolumn{2}{|c|}{$\mathbf{S}$} & \multicolumn{2}{|c|}{ CS } & \multicolumn{2}{|c|}{ TS } & \multicolumn{2}{|c|}{ STS } & \multirow{2}{*}{$\begin{array}{c}\text { Rata - } \\
\text { rata }\end{array}$} \\
\hline & $\mathbf{F}$ & $\%$ & $\mathbf{F}$ & $\%$ & $\mathbf{F}$ & $\%$ & $\mathbf{F}$ & $\%$ & $\mathbf{F}$ & $\%$ & \\
\hline $\begin{array}{l}\text { Tersedia fasilitas } \\
\text { yang layak untuk } \\
\text { bersuci }\end{array}$ & 0 & 0,0 & 0 & 0,0 & 14 & 10,0 & 99 & 70,7 & 27 & 19,3 & 4,09 \\
\hline $\begin{array}{l}\text { Terjamin kehalalan } \\
\text { makanan dan } \\
\text { minuman dengan } \\
\text { sertifikasi halal } \\
\text { MUI }\end{array}$ & 0 & 0,0 & 0 & 0,0 & 5 & 3,6 & 107 & 76,4 & 28 & 20,0 & 4,16 \\
\hline $\begin{array}{l}\text { Menyediakan paket } \\
\text { perjalanan/wisata } \\
\text { yang sesuai dengan } \\
\text { kriteria pariwisata } \\
\text { halal }\end{array}$ & 0 & 0,0 & 0 & 0,0 & 2 & 1,4 & 104 & 74,3 & 34 & 24,3 & 4,23 \\
\hline $\begin{array}{l}\text { Tersedianya terapis } \\
\text { yang khusus pria } \\
\text { atau khusus wanita }\end{array}$ & 0 & 0,0 & 0 & 0,0 & 9 & 6,4 & 112 & 80,0 & 19 & 13,6 & 4,07 \\
\hline $\begin{array}{l}\text { Mampu } \\
\text { melaksanakan } \\
\text { nilai-nilai Islami } \\
\text { dalam menjalankan } \\
\text { tugas }\end{array}$ & 0 & 0,0 & 0 & 0,0 & 4 & 2,9 & 109 & 77,9 & 27 & 19,3 & 4,16 \\
\hline \multicolumn{11}{|c|}{ Grand Mean } & 4,14 \\
\hline
\end{tabular}

Sumber: data primer, diolah (2019)

Hasil analisis variabel Amenitas (X2) pada penelitian ini memiliki rata-rata skor tertinggi pada indikator pertanyaan ketiga, yaitu Menyediakan paket perjalanan/wisata yang sesuai dengan kriteria pariwisata halal dengan skor nilai rata-rata 4,23\%. Sementara, skor terendah terdapat pada indikator pertanyaan keempat, yaitu Tersedianya terapis yang khusus pria atau khusus wanita sebesar 4,07\%. Nilai tersebut menunjukkan bahwa responden setuju dengan adanya paket wisata yang sesuai dengan kriteria pariwisata halal. Dengan hal ini, strategi pengembangan pada destinasi wisata Gunung Bromo dapat diperkuat.

Tentang Aksesibiltas (X3) yang diperoleh dari hasil jawaban responden didapatkan perhitungan yang ditunjukkan pada tabel 11. 
Tabel 11. Hasil Diskripsi Jawaban Responden tentang Aksebilitas (X3)

\begin{tabular}{|l|c|c|c|c|c|c|c|c|c|c|c|}
\hline \multirow{2}{*}{ Indikator } & \multicolumn{2}{|c|}{ SS } & \multicolumn{2}{|c|}{ S } & \multicolumn{2}{c|}{ CS } & \multicolumn{2}{c|}{ TS } & \multicolumn{2}{c|}{ STS } & $\begin{array}{c}\text { Rata - } \\
\text { rata }\end{array}$ \\
\cline { 2 - 10 } & $\mathbf{F}$ & $\mathbf{\%}$ & $\mathbf{F}$ & $\mathbf{\%}$ & $\mathbf{F}$ & $\mathbf{\%}$ & $\mathbf{F}$ & $\mathbf{\%}$ & $\mathbf{F}$ & $\mathbf{\%}$ & \\
\hline $\begin{array}{l}\text { Adanya } \\
\text { ketersediaan } \\
\text { transportasi yang } \\
\text { memadahi }\end{array}$ & 0 & 0,0 & 1 & 0,7 & 8 & 5,7 & 91 & 65,0 & 40 & 28,6 & 4,21 \\
\hline $\begin{array}{l}\text { Keadaan jalan } \\
\text { yang nyaman dan } \\
\text { tidak berlubang }\end{array}$ & 0 & 0,0 & 1 & 0,7 & 25 & 17,9 & 99 & 70,7 & 15 & 10,7 & 3,91 \\
\hline $\begin{array}{l}\text { Ketersediaan area } \\
\text { parkir yang luas }\end{array}$ & 0 & 0,0 & 1 & 0,7 & 27 & 19,3 & 88 & 62,9 & 24 & 17,1 & 3,96 \\
\hline $\begin{array}{l}\text { Adanya keamaan } \\
\text { di sekitar } \\
\text { kawasan wisata } \\
\text { bagi pengemudi }\end{array}$ & 0 & 0,0 & 2 & 1,4 & 29 & 14,3 & 89 & 63,6 & 29 & 20,7 & 4,04 \\
\hline
\end{tabular}

Sumber: data primer, diolah (2019)

Hasilnya menunjukkan bahwa berdasarkan variabel Aksesbilitas, hasil analisis jawaban responden memiliki skor nilai rata-rata tertinggi sebesar 4,21\% pada indikator pertanyaan pertama, yaitu Adanya ketersediaan transportasi yang memadahi. Sedangkan, skor nilai ratarata terendah sebesar 3, 96\% terdapat pada indikator pertanyaan kedua, yaitu Keadaan jalan yang nyaman dan tidak berlubang. Hal ini membuktikan membuktikan bahwa responden menyetujui bahwa ketersediaan transportasi yang memadahi memperkuat strategi pengembangan pariwisata Gunung Bromo. Terkait dengan hasil analisis tentang Strategi Pengembangan (Y), hasilnya pengolahan perhitungannya ditunjukkan pada tabel 12 .

Tabel 12. Hasil Diskripsi Jawaban Responden tentang Strategi Pengembangan (Y)

\begin{tabular}{|c|c|c|c|c|c|c|c|c|c|c|c|}
\hline \multirow[t]{2}{*}{ Indikator } & \multicolumn{2}{|c|}{ SS } & \multicolumn{2}{|c|}{$\mathbf{S}$} & \multicolumn{2}{|c|}{$\mathrm{CS}$} & \multicolumn{2}{|c|}{ TS } & \multicolumn{2}{|c|}{ STS } & \multirow{2}{*}{$\begin{array}{r}\text { Rata - } \\
\text { rata }\end{array}$} \\
\hline & $\mathbf{F}$ & $\%$ & $\mathbf{F}$ & $\%$ & $\mathbf{F}$ & $\%$ & $\mathbf{F}$ & $\%$ & $\mathbf{F}$ & $\%$ & \\
\hline $\begin{array}{l}\text { Kawasan Gunung } \\
\text { Bromo masih asti } \\
\text { tanpa polusi }\end{array}$ & 0 & 0,0 & 0 & 0,0 & 7 & 5,0 & 104 & 74,3 & 29 & 20,7 & 4,16 \\
\hline $\begin{array}{l}\text { Kawasan Gunung } \\
\text { Bromo memiliki } \\
\text { keunikan yang } \\
\text { tidak ada di } \\
\text { wilayah wisata } \\
\text { lain }\end{array}$ & 0 & 0,0 & 0 & 0,0 & 2 & 1,4 & 124 & 88,6 & 14 & 10,0 & 4,09 \\
\hline $\begin{array}{l}\text { Lahan di sekitar } \\
\text { wilayah wisata } \\
\text { dapat } \\
\text { dioptimalkan } \\
\text { dengan baik }\end{array}$ & 0 & 0,0 & 0 & 0,0 & 6 & 4,3 & 109 & 77,9 & 25 & 17,9 & 4,14 \\
\hline $\begin{array}{l}\text { Banyaknya mata } \\
\text { pencaharian yang } \\
\text { beragam. }\end{array}$ & 0 & 0,0 & 0 & 0,0 & 9 & 6,4 & 120 & 85,7 & 11 & 7,9 & 4,01 \\
\hline & & & & ranc & M & & & & & & 4,1 \\
\hline
\end{tabular}

Sumber: data primer, diolah (2019) 
Berdasarkan variabel Strategi Pengembangan (Y), hasil analisis jawaban kuesioner menunjukkan bahwa skor nilai rata-rata tertinggi sebesar $4,16 \%$ terdapat pada indikator pertanyaan pertama, yaitu Kawasan Gunung Bromo masih asri tanpa polusi. Sedangkan skor terendah $4,01 \%$ terdapat pada indikator pertanyaan keempat, yaitu Banyaknya mata pencaharian yang beragam. Nilai tersebut membuktikan bahwa menciptakan kawasan Gunung Bromo yang masih asri tanpa polusi memperkuat staregi pengembangan wisata Gunung Bromo.

Selanjutnya dilakukan uji hipotesis berdasarkan hasil Uji Regresi Linier Berganda secara Uji Parsial (T) dan Uji Simultan (F). Hasil uji regresi linear berganda pada penelitian ini disajikan pada tabel 13.

Tabel 13. Hasil Uji Regresi Liniear Berganda

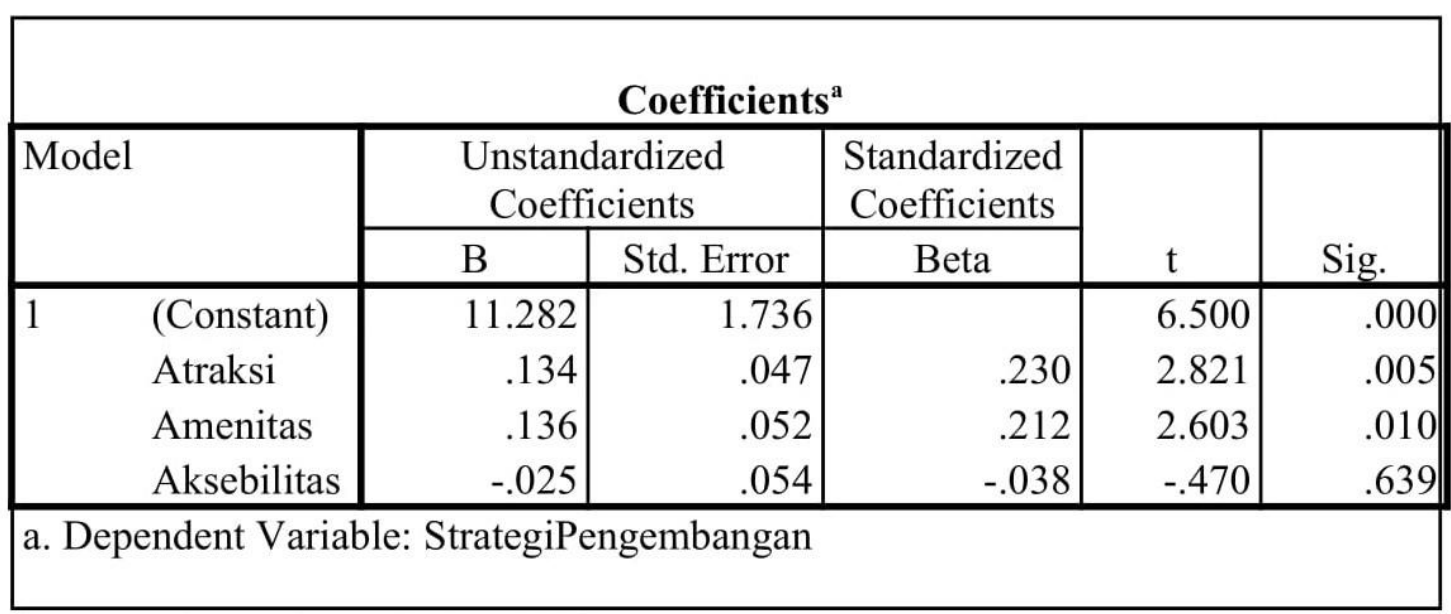

Sumber: Data Primer Diolah, 2019.

Seperti ditunjukkan pada tabel 13, dari persamaan regresi linier berganda $\quad(\mathrm{Y}=$ $11,282+0,134 \mathrm{X} 1+0,136 \mathrm{X} 2-0,25 \mathrm{X} 3+\mathrm{e})$, dapat diartikan bahwa:

1) Nilai konstanta sebesar 11,282 mengedifikasi jika variabel independent yaitu Atraksi, Amenitas, Aksesbilitas dianggap konsta, maka nilai Strategi Pengembangan sebesar 11,282 ;

2) Nilai koefisien $X 1$ sebesar 0,134 , artinya semakin tinggi atraksi maka adanya strategi pengembangan akan semakin meningkat sebesar 0,134 ;

3) Nilai koefisien $X 2$ sebesar 0,136, artinya semakin tinggi amenitas maka adanya strategi pengembangan akan semakin meningkat sebesar 0,178 ;

4) Nilai koefisien $X 3$ sebesar -0,025, artinya aksebilitas tidak memiliki pengaruh pada strategi pengembangan.

Pada hasil Uji Parsial (T) untuk untuk mengetahui besar pengaruh variabel bebas terhadap variabel terikat secara parsial, dasar yang digunakan adalah dengan membandingkan nilai signifikan yang dihasilkan dengan alpha 0,05. Hasil uji T disajikan pada tabel 14 . 
Tabel 14. Hasil Uji T

\begin{tabular}{|c|c|c|c|c|c|c|}
\hline \multicolumn{7}{|c|}{ Coefficients $^{\mathrm{a}}$} \\
\hline \multirow{2}{*}{\multicolumn{2}{|c|}{ Model }} & \multicolumn{2}{|c|}{\begin{tabular}{c|} 
Unstandardized \\
Coefficients
\end{tabular}} & \multirow{2}{*}{$\begin{array}{c}\begin{array}{c}\text { Standardized } \\
\text { Coefficients }\end{array} \\
\text { Beta } \\
\end{array}$} & \multirow[b]{2}{*}{$\mathrm{t}$} & \multirow[b]{2}{*}{ Sig. } \\
\hline & & $\mathrm{B}$ & Std. Error & & & \\
\hline \multirow[t]{4}{*}{1} & (Constant) & 11.282 & 1.736 & & 6.500 & .000 \\
\hline & Atraksi & .134 & .047 & .230 & 2.821 & .005 \\
\hline & Amenitas & .136 & .052 & .212 & 2.603 & .010 \\
\hline & Aksebilitas & -.025 & .054 & -.038 & -.470 & .639 \\
\hline
\end{tabular}

Sumber: Data Primer Diolah, 2019.

Berdasarkan tabel 14, nilai signifikan dari setiap variabel bebas diuraikan sebagai berikut.

1) Variabel Atraksi

Variabel Atraksi menunjukkan nilai thitung sebesar 2,821 dan nilai signifikan sebesar 0,005. Karena taraf signifikan yang digunakan adalah 0,05 , maka nilai signifikan dapat dikatakan kurang dari 0,05. Jadi, kesimpulannya adalah H1 diterima. Dengan demikian, variabel Atraksi secara parsial berpengaruh positif terhadap strategi pengembangan.

2) Variabel Amenitas

Variabel kualitas produk menunjukkan nilai thitung sebesar 2,603 dan nilai signifikan sebesar 0,010. Karena taraf signifikan yang digunakan adalah 0,05, maka nilai signifikan dapat dikatakan kurang dari 0,05. Kesimpulannya adalah H2 diterima. Dengan demikian, variabel amenitas secara parsial berpengaruh positif terhadap strategi pengembangan.

3) Variabel Aksesbilitas

Variabel aksesbilitas menunjukkan nilai $t_{\text {hitung }}$ sebesar $-0,470$ dan nilai signifikan sebesar 0,679. Karena taraf signifikan yang digunakan adalah 0,05, maka nilai signifikan dapat dikatakan lebih dari 0,05. Kesimpulannya adalah H3 ditolak. Dengan demikian variabel aksesbilitas secara parsial berpengaruh negatif terhadap strategi pengembangan.

Sementara, Uji Simultan (F) dilakukan untuk mengukur ketepatan fungsi regresi dalam menaksir nilai aktual (goodness of fit). Uji $\mathrm{F}$ ini juga dilakukan untuk mengetahui cocok atau tidaknya model yang digunakan. Hasil uji F disajikan pada tabel 15. 
Tabel 15. Hasil Uji Simultan (F)

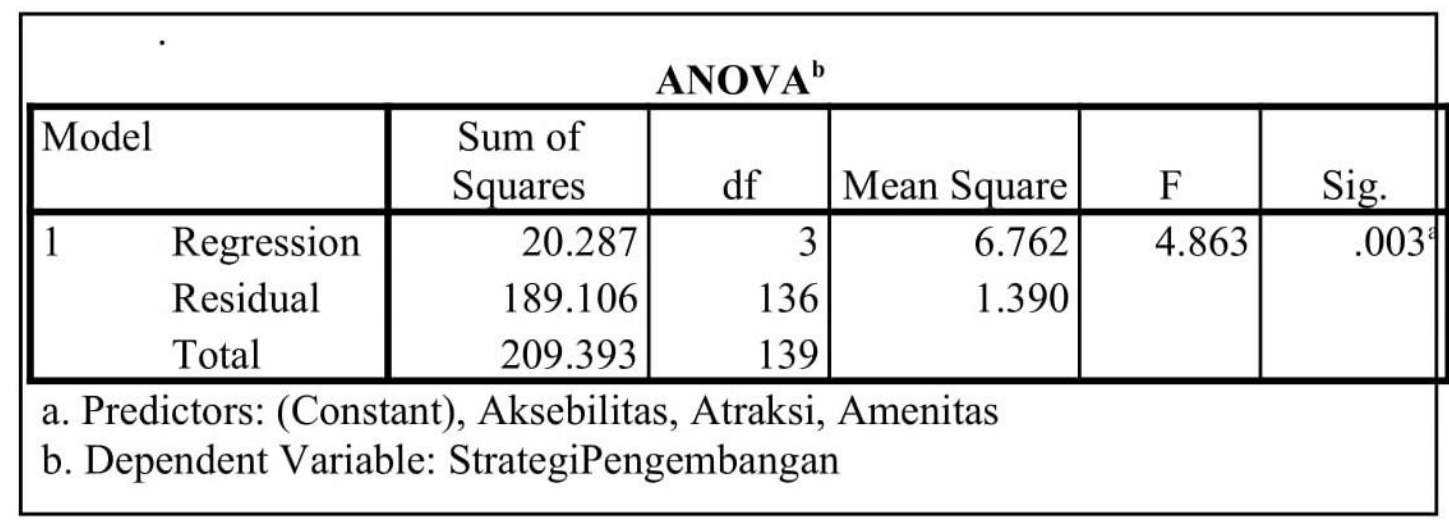

Sumber: Data Primer Diolah, 2019.

Berdasarkan tabel 15 , nilai $\mathrm{F}$ hitung sebesar 4,863 dengan tingkat signifikansi dari hasil uji $\mathrm{F}$ sebesar $0,003<\alpha(0,05)$, maka secara simultan kepercayaan, kualitas produk, promosi, dan harga memiliki pengaruh signifikan terhadap minat pembelian. Kesimpulannya adalah H4 diterima.

\section{KESIMPULAN DAN SARAN}

Berdasarkan hasil analisis dan pembahasan dapat ditarik simpulan sebagai berikut.

1. Variabel Atraksi secara langsung berpengaruh positif dan signifikan terhadap Strategi Pengembangan wisata halal Gunung Bromo.

2. Variabel Amenitas secara langsung berpengaruh positif dan signifikan terhadap Strategi Pengembangan wisata halal Gunung Bromo.

3. Variabel Aksesbilitas secara langsung berpengaruh negative dan tidak signifikan terhadap Strategi Pengembangan wisata halal Gunung Bromo.

4. Variabel Atraksi, Amenitas dan Aksesbilitas secara bersama-sama berpengaruh positif dan signifikan terhadap Strategi Pengembangan wisata halal Gunung Bromo.

Beberapa saran guna perbaikan penelitian ini perlu disajikan. Bagi pemerintah pusat, diharapkan untuk lebih memperhatikan sarana prasarana di wilayah destinasi wisata pada umumnya, khususnya penerapan 3A. Sedangkan, pemerintah daerah diharapkan lebih memperhatikan upaya peningkatan aksesbilitas khususnya di kawasan wisata Gunung Bromo. Penelitian ini hanya dilakukan pada destinasi wisata Gunung Bromo. Diharapkan bagi peneliti selanjunya dapat meneliti objek wisata lain di Indonesia, khususnya di Kabupaten Probolinggo.

\section{DAFTAR PUSTAKA}

Abdulhaji Sulfi dan Ibnu Sina Hi. Yusuf. (2016). Pengaruh Atraksi, Aksesibilitas, Dan Fasilitas Terhadap Citra Objek Wisata Danau Tolire Besar Di Kota Ternate. Jurnal Penelitian Humano Vol. 7 No. 2 Edisi November 2016.pp 134-148.

Cannon, Joseph P., William D. Perreault Jr. dan Jerome McCarthy. (2008). Alih Bahasa: Diana Angelica dan Ria Cahyani. Dasar-Dasar Pemasaran: Pendekatan Manajerial Global. Buku 2. Edisi 16. Jakarta.: Salemba Empat.

Çakici, A Celil., Harman, Serhat., (2007), Importance of Destination Attributes Affecting Destination Choice Of Turkish Birdwatchers, Journal of Commerce \& Tourism 
Education Faculty, Year: 2007 No: 1, Ticaret ve Turizm Egitim Fakültesi Dergisi Yıl: 2007 Say1: 1, page 131-145.

Dispopar Kab. Probolinggo, Grafik Kunjungan Wisata Gunung Bromo Tahun 2016-2018.

Ghozali, Imam. (2005). Aplikasi Analisis Multivariate dengan Program SPSS. Semarang: BP UNDIP.

Hair, J.F. et al. (2010). Multivariate Data Analysis A Global Perspective. Pearson: Seven Edition.

Hasan, M. Iqbal. (2005). Pokok-Pokok Materi Statistik 2, Cetakan ketiga. Jakarta: PT Bumi Aksara.

Ratman, D. R. (n.d.). (2016).Strategi Pengembangan Kepariwisataan Indonesia . Retrieved Desember 11, from Wonderful Indonesia.

Riduwan. (2012). Metode \& Teknik Menyusun Proposal Penelitian. Bandung: Alfabeta.

Spillane, J.J. (1997), Pariwisata Indonesia Sejarah dan Prospeknya, Yogyakarta: Kanisius.

Sugiyono. (2011). Metode Penelitian Kuantitatif, Kualitatif dan R\&D. Bandung: Alfabeta. (2012). Metode Penelitian Kuantitatif Kualitatif dan R\&D. Bandung: Alfabeta.

Suharyadi dan Purwanto S.K. (2003). Statistika untuk Ekonomi dan Keuangan Modern, Jilid 1. Jakarta: Salemba Empat.

Tjiptono, Fandy. (2004). Manajemen Jasa. Edisi pertama. Yogyakarta: Andi Offset. 2007). Strategi Pemasaran, Edisi Kedua. Yogyakarta: Andi Offset.

UU No.10 Tahun 2009. 